\title{
ALAVANCAGEM FINANCEIRA, ESTRUTURA PATRIMONIAL E A VOLATILIDADE DOS ATIVOS NEGOCIADOS NA B3
}

\author{
Financial leverage, capital structure and the volatility of assets traded \\ on B3
}

Fabio Michel Oliveira

E-mail: michelmike23@hotmail.com

Mestre em Economia Aplicada pela Universidade Federal de Pelotas; Bacharel em Ciências Econômicas pela Universidade Católica de Petrópolis; Professor de Matemática no Instituto São Pedro de Alcântara.

Endereço para contato: Avenida Getúlio Vargas, 1456, Quitandinha, 25651-078, Petrópolis, Rio de Janeiro. https://orcid.org/0000-0002-8767-4264

Regis Augusto Ely E-mail: regisaely@gmail.com Doutor em Economia pela Universidade de Brasília; Pós-doutorando na Escola de Economia de São Paulo da Fundação Getúlio Vargas; Bolsista do Conselho Nacional de Desenvolvimento Científico e Tecnológico (CNPq); https://orcid.org/0000-0002-2468-3761

Rodrigo Nobre Fernandez

E-mail: rodrigonobrefernandez@gmail.com

Doutor em Economia pela Universidade Federal do Rio Grande do Sul; Pós-doutorando na

Universidade Federal do Rio Grande;

Bolsista da Coordenação de Aperfeiçoamento de Pessoal de Nível Superior (CAPES). https://orcid. org/0000-0001-8596-2898 


\section{Resumo}

Este artigo possui o objetivo de mensurar o efeito da alavancagem financeira e da estrutura patrimonial das empresas listadas na B3 (Brasil, Bolsa, Balcão) na volatilidade de seus ativos negociados em Bolsa. Para isso, estimou-se um modelo de painel com efeitos fixos utilizando dados trimestrais e calculou-se a volatilidade trimestral por meio do desvio padrão dos preços de fechamento diários dos ativos. Os dados utilizados incluem os balanços trimestrais desde o período de 2010 até o primeiro trimestre de 2017, e o preço dos ativos negociados em Bolsa. Os resultados demonstram que a estrutura de capital das empresas influencia a volatilidade de seus ativos, especialmente variáveis, como o grau de alavancagem, a composição do endividamento e a imobilização do patrimônio. Empresas com níveis maiores de endividamento são mais sensíveis a esses efeitos, bem como empresas do setor de varejo e transportes.

Palavras-chave: Alavancagem financeira. Volatilidade e estrutura patrimonial.

\section{Abstract}

This article aims to measure the effect of financial leverage and capital structure of companies listed on B3 (Brasil, Bolsa, Balcão) on the volatility of their publicly traded Assets. For this, we estimate a panel model with fixed effects using quarterly data and calculate the quarterly volatility through the standard deviation of the daily closing prices of the Assets. The data used includes the quarterly balance sheets during the period from 2010 to the first quarter of 2017 and the price of the assets traded on the stock exchange. The results show that the capital structure of companies influences the volatility of their assets, especially variables such as leverage, composition of the debt and fixed assets. Companies with higher levels of debt are more sensitive to these effects, as are companies in the retail and transportation sector.

Keywords: Financial leverage. Volatility and capital structure.

\section{INTRODUÇÃO}

A estrutura de capital é um dos temas centrais da Teoria das Finanças Corporativas, pois se refere-se forma como as empresas utilizam o capital próprio e o capital de terceiros para financiarem seus negócios. A maneira como as empresas utilizam sua estrutura de capital para financiarem novas atividades produtivas pode enviar sinais ao mercado acionário, afetando a volatilidade dos ativos negociados em Bolsa. Apesar de temas relacionados à estrutura de capital das empresas serem amplamente discutidos na literatura (Rajan \& Zingales, 1995), as evidências para o Brasil são mais escassas, especialmente no que diz respeito aos efeitos da estrutura de capital na volatilidade das ações das empresas.

A obra clássica de Modigliani e Miller (1958) parte dos pressupostos em que a estrutura de capital é irrelevante para o valor das empresas. A proposição contrapunha a teoria convencional que defendia uma estrutura ótima de capital, a qual minimizava o custo de capital da empresa e maximizava a riqueza dos seus proprietários. 
Com o objetivo de inserir assimetria de informações nos estudos de Modigliani e Miller (1958), surgiu a teoria de Kraus e Litzenberger (1973), que afirma a estrutura ótima de capital sendo uma escolha (trade-off) entre os benefícios da alavancagem e os custos de falência. Nesse mesmo sentido, Myers e Majluf (1984) elaboraram the pecking order theory, que é derivada da assimetria de informações do problema de agente principal que os administradores enfrentam entre os acionistas antigos e novos investidores. A teoria de Welch (2004) já faz parte de uma nova tendência entre a relação da estrutura de capital e retornos; ela aborda a variação do valor das empresas e como se comporta o endividamento.

A escolha das empresas entre financiar suas atividades de investimento por meio de capital próprio ou capital de terceiros pode influenciar a percepção dos investidores, refletindo a volatilidade das ações das empresas de capital aberto. Esse tema foi estudado por artigos recentes, como os de Campbell e Rogers (2018), Chon e Kim (2019) e DeAngelo e Roll (2015). Para o Brasil, Cardoso, Carr, e Rogers (2019) estudaram como a governança corporativa afeta a volatilidade dos retornos acionários, enquanto que Oliveira e Kayo (2019) estudaram como o setor pode afetar as decisões sobre a estrutura de capital das empresas.

Dentro desse contexto, este trabalho busca verificar o impacto da estrutura patrimonial sobre a volatilidade das empresas listadas na B3 (Brasil, Bolsa, Balcão). Tem-se como hipótese principal que há efeitos da alavancagem financeira a da estrutura de capital sobre o valor de uma empresa. Para realizar tal tarefa, tem-se uma amostra que abrange as empresas que possuíam capital aberto no primeiro trimestre de 2010 e que ainda estavam listadas na B3 até o primeiro trimestre de 2017. Destaca-se que essa Bolsa de Valores é a $20^{a}$ maior Bolsa do mundo e a maior Bolsa de Valores da América Latina em termos de capitalização, com 824 bilhões de dólares e 349 empresas em dezembro de 2016. O modelo econométrico a utilizado é o de dados em painel com efeito fixo.

Os resultados indicam que a alavancagem financeira possui um efeito positivo e significativo sobre a volatilidade. Com relação às variáveis que determinam a estrutura de capital das empresas, tem-se que o tamanho e o grau de liquidez são fatores que influenciam negativamente a volatilidade. Além disso, o retorno sobre o endividamento e o imobilizado apresentam efeitos positivos sobre a volatilidade, sendo este último apenas nos setores de construção civil e de transportes.

Em suma, este estudo está estruturado em cinco partes, tendo por início esta introdução. Na segunda seção é feita a revisão da literatura, em que são abordados alguns conceitos sobre alavancagem e volatilidade. Posteriormente, apresentam-se a base de dados e os métodos a serem utilizados. Na penúltima seção apresentam-se os resultados e suas respectivas análises, e, por fim, a última seção aborda as considerações finais. 


\section{REVISÃO DA LITERATURA}

O trabalho pioneiro referente ao estudo da estrutura de capital das empresas é o de Modigliani e Miller (1958). Os autores apresentam como resultado principal que não existe uma estrutura de capital ótima e todas as estruturas são equivalentes do ponto de vista do custo de capital em concorrência perfeita.

Contudo, o primeiro estudo a verificar a estrutura de capital em mercados de concorrência imperfeita é o de Kraus e Litzenberger (1973), que introduz taxas corporativas e custos de falência e um ambiente de mercados completos. Logo, a estrutura ótima de capital das empresas envolve uma escolha entre vantagens fiscais de uma dívida e custos de falência.

Sob um prisma de assimetria informacional, Myers e Majluf (1984) atacam o problema de conflito de interesses quando os administradores estão diante de uma oportunidade de negócio. Argumentam que na presença de informações assimétricas sobre o real valor dos ativos da empresa, os administradores podem se posicionar ao lado dos acionistas mais antigos do que dos novos investidores. Segundo esses autores, as empresas têm que emitir títulos de dívidas seguros ou emitir ações em caso de oportunidades de negócios (projeto); essa emissão é equivalente ao valor do projeto e não há taxas, custos de transação ou qualquer outra imperfeição no mercado. Caso a empresa não aproveite a oportunidade de negócio no momento, a oportunidade desaparece. Com assimetria de informação, quando as ações são emitidas para financiar um novo investimento, o preço das ações cairá, entretanto, se a firma emite títulos seguros de dívidas, isso não acontece. Assim, a empresa nunca emitirá ações quando existe a opção de emitir títulos de dívidas.

Em termos empíricos, há diversos trabalhos que estudam os possíveis determinantes da estrutura de capital das empresas. Baker (1973) utilizou Mínimos Quadrados de Dois Estágios (MQ2E) e encontrou que a lucratividade afeta negativamente a alavancagem financeira. Bradley, Jarrel, e Kim (1984), em uma análise feita utilizando um modelo ANOVA e Mínimos Quadrados Ordinários (MQO) para a indústria americana, mostraram que a alavancagem financeira é negativamente relacionada a despesas não tributáveis.

Em outro contexto, Titman e Wessels (1988) verificaram que o nível de despesa está negativamente relacionado com a unicidade da linha negócios da empresa, ou seja, quanto mais concentrado é o mercado em que a empresa está estabelecida, menor é a alavancagem financeira. Adicionalmente, encontraram evidências de que os custos de transações podem ser um fator importante para a escolha de estrutura de capital.

Em um estudo com dados de corte para os países do Grupo dos Sete (G7), Rajan e Zingales (1995) encontraram que fatores como a imobilização, a oportunidade de crescimento (marketto-book), o tamanho e lucratividade eram importantes para explicar a estrutura de capital. Os 
autores enfatizam que por mais que as empresas estejam sob a mesma legislação e o sobre o mesmo ambiente institucional, essas variáveis podem afetar cada empresa de forma distinta.

Dentro desse escopo, Bauer (2004) também analisa os determinantes da estrutura de capital financeira das empresas situadas na Bolsa de Valores de Praga, adicionando dummies referentes à indústria que cada empresa pertence e à volatilidade dos ativos. Os resultados indicam que a alavancagem financeira é determinada pelos mesmos fatores discutidos em Rajan e Zingales (1995). Entretanto, a variável de volatilidade não se mostrou estatisticamente significativa. A alavancagem financeira apresentou uma relação positiva com o tamanho das empresas, mas uma relação negativa com a lucratividade.

No mesmo contexto, mas em uma análise para a economia americana, Johnson (2003) encontrou que as dívidas de curto prazo atenuam o efeito negativo da oportunidade de crescimento sobre a alavancagem financeira. $O$ autor argumenta que a despesa de curto prazo aumenta o risco de liquidez, o qual possui um efeito negativo sobre a alavancagem financeira. Dessa forma, o índice de liquidez é um dos possíveis determinantes da estrutura de capital.

Como reiteram Eckbo e Norli (2005), o aumento das razões de despesas com endividamento e alavancagem afetam a volatilidade das empresas. De acordo com as constatações dos autores, a alavancagem financeira impulsiona os retornos por meio de empréstimos e a redução da alavancagem também diminui o risco dos retornos com relação aos fatores da alavancagem. Adicionalmente, empresas que estão estabelecidas no mercado primário de ações possuem menor alavancagem financeira do que empresas já estabelecidas no mercado de ações e que possuem baixo crescimento dos preços das ações.

Em uma análise em dados em painel para o continente asiático, Deesomsak, Paudyal e Pescetto (2004) encontraram que os efeitos positivos do tamanho da empresa e os efeitos negativos de crescimento de oportunidade, despesas não tributáveis, liquidez e preço por ação estão de acordo com a maioria das teorias sobre estrutura de capital e os determinantes da alavancagem financeira variam de país e região com provável causa do ambiente jurídico e institucional que a empresa atua.

Similarmente, Chen (2004) testou se a teoria moderna da estrutura de capital se aplicava para as empresas chinesas onde a maioria das empresas listadas na Bolsa são estatais. Concluiu que algumas variáveis que são importantes para determinar as decisões de alavancagem no Ocidente também afetavam as empresas chinesas, enquanto que lucratividade e oportunidades de crescimento apresentaram significância, volatilidade, custos de falência e despesas não tributáveis insignificantes. Isso se deve pelo fato de o Governo ser o maior acionista e também dono dos bancos, logo, o custo de capital não possui efeito sobre as empresas e assim incorre em menos riscos. As diferenças institucionais entre a China e o Ocidente estipulam diferentes determinantes para a estrutura de capital das firmas chinesas. 
Da mesma forma, Jong, Kabir, e Nguyen (2008), em uma análise cross section para 29 países situados nos continentes asiáticos, europeu e americano, observaram que os determinantes da estrutura de capital não são equivalentes entre si. Desse modo, faz-se necessária uma análise dos fatores específicos de cada nação. Adicionalmente, Céspedes, González, e Molina (2010) encontraram evidências empíricas de que o tamanho, o crescimento de oportunidade e o imobilizado são fatores significantes e importantes para descreverem a alavancagem financeira na América Latina.

No período de 1990 a 2000, Bouchaud, Matacz, e Potters (2001) analisaram 437 ações americanas que constituem o índice $S \& P 500$, investigaram o efeito alavancagem correspondente a uma correlação negativa entre volatilidade futura e retornos passados. Os autores encontraram que essa correlação é moderada e a alavancagem financeira decresce em poucos meses para ações individuais, sendo muito mais forte e decrescendo rapidamente para portfólios de ações.

No contexto brasileiro, Forte, Barros, e Nakamura (2013) realizaram estimativas para os determinantes da estrutura de capital das pequenas e médias empresas do Estado de São Paulo. Usando o Estimador de Sistema para o Método dos Momentos Generalizados (GMM-SYS), os autores encontraram uma relação negativa muito forte entre alavancagem financeira e lucratividade e alavancagem e crescimento de oportunidade.

Em uma estrutura de séries temporais, Choi e Richardson (2016) afirmaram que a alavancagem financeira é importante para explicar movimentos na volatilidade patrimonial. As mudanças na volatilidade patrimonial são causadas pela alavancagem financeira e pelos choques dos retornos. Complementarmente, Ericsson, Huang, e Mazzotta (2016) confirmaram que a alavancagem financeira afeta a volatilidade dos retornos, em que uma mudança na alavancagem financeira possui um efeito longo na volatilidade dos retornos das empresas, o que, segundo os autores, reforça uma relação entre volatilidade patrimonial e razões de despesas.

Por fim, Alaoui, Bacha, e Masih (2017) verificaram que, para os 10 maiores países da Europa, os retornos das empresas e a volatilidade variam com mudanças na estrutura de capital, considerando níveis de dívidas diferentes (abaixo de $33 \%$ e acima de $33 \%$, despesas/ ativo total). Adicionalmente, encontraram um efeito prejudicial do endividamento sobre a volatilidade para as empresas com alto endividamento; isso quer dizer que o endividamento aumenta a volatilidade. Enquanto para as firmas com baixo nível de endividamento o efeito sobre a volatilidade é positivo para as empresas, ou seja, diminui a volatilidade.

Outros artigos mais recentes estudaram como a escolha das empresas entre financiar suas atividades de investimento por meio de capital próprio ou capital de terceiros pode influenciar a percepção dos investidores, e consequentemente a volatilidade das ações das empresas de capital aberto. Chon e Kim (2019), ao estudarem empresas da Coréia do 
Sul, encontraram evidências de que firmas com uma estrutura de capital mais volátil são caracterizadas por níveis mais altos de vulnerabilidade financeira. Já Campbell e Rogers (2018) e DeAngelo e Roll (2015) estudaram as características e a volatilidade da estrutura de capitais de empresas de capital aberto europeias e americanas, respectivamente. Para o Brasil, Cardoso et al. (2019) estimaram como a governança corporativa afeta a volatilidade dos retornos acionários, enquanto que Oliveira e Kayo (2019) estudaram como o setor em que a empresa atua pode afetar suas decisões sobre a estrutura de capital.

\section{DESCRIÇÃO DOS DADOS}

A amostra foi constituída a partir de informações dos balanços trimestrais obtidos da B3 durante o período de 2010 até o primeiro trimestre de 2017. As empresas que abriram capital após 2010 foram excluídas da amostra de modo a manter um painel de informações contábeis balanceado. A decisão de utilizar dados a partir de 2010 ocorre pelo fato de que as observações anteriores a esse período são suscetíveis de grandes variações em razão da crise de 2008.

Para o cálculo da volatilidade dos retornos foi selecionado o ativo mais líquido de cada empresa, calculado pelo volume de negócios mensais. Considerou-se apenas as empresas que seu ativo mais líquido possuía o volume mínimo de 15 transações mensais, descartando, assim, ativos de baixa liquidez. A inclusão desses ativos nas estimativas poderia superestimar a volatilidade, uma vez que ativos com baixa liquidez costumam possuir alta volatilidade em decorrência de problemas associados a transações não sincronizadas.

A Tabela 1 apresenta o resumo das variáveis de controle, bem como as fórmulas e componentes de cada um dos indicadores utilizados, e trabalhos da literatura que também utilizaram esses indicadores:

Tabela 1

Resumo descritivo das variáveis

\begin{tabular}{|c|c|c|}
\hline Variável & Definição & Literatura \\
\hline Liquidez geral & $\begin{array}{l}\text { (Ativo circulante + Ativo realizável } \\
\text { em longo prazo)/Passivo circulante } \\
+ \text { Passivo não cirulante }\end{array}$ & $\begin{array}{l}\text { Deesomsak et al. (2004), Eckbo e Norli } \\
\text { (2005) e Jong et al. (2008) }\end{array}$ \\
\hline $\begin{array}{l}\text { Composição do endi- } \\
\text { vidamento }\end{array}$ & $\begin{array}{l}\text { Passivo circulante/(Passivo circulan- } \\
\text { te + Passivo não circulante) }\end{array}$ & Eckbo e Norli (2005) \\
\hline $\begin{array}{l}\text { Grau de alavancagem } \\
\text { financeira }\end{array}$ & $\begin{array}{l}\text { Lucro cperacional/(Lucro cperacio- } \\
\text { nal-Despesas Financeiras) }\end{array}$ & $\begin{array}{l}\text { Bauer (2004), Bradley et al. (1984), Chen } \\
\text { (2004), Deesomsak et al. (2004), Eckbo e } \\
\text { Norli (2005), Johnson (2003), Jong et al. } \\
\text { (2008) e Rajan e Zingales (1995) }\end{array}$ \\
\hline
\end{tabular}




\begin{tabular}{|c|c|c|}
\hline Variável & Definição & Literatura \\
\hline & & $\begin{array}{l}\text { Alaoui et al. (2017), Céspedes et al. (2010), } \\
\text { Choi e Richardson (2016), Forte et al. (2013) e } \\
\text { Gill, Biger, e Mathur (2011) }\end{array}$ \\
\hline \multirow[t]{2}{*}{$\begin{array}{l}\text { Imobilização do patri- } \\
\text { mônio líquido }\end{array}$} & $\begin{array}{l}\text { Ativo permanente/Patrimônio } \\
\text { líquido }\end{array}$ & $\begin{array}{l}\text { Bauer (2004), Chen (2004), Deesomsak et al. } \\
\text { (2004), Eckbo e Norli (2005), Johnson (2003), } \\
\text { Jong et al. (2008) e Rajan e Zingales (1995) }\end{array}$ \\
\hline & & $\begin{array}{l}\text { Céspedes et al. (2010), Choi e Richardson } \\
\text { (2016) e Gill et al. (2011) }\end{array}$ \\
\hline ROE & $\begin{array}{l}\text { Lucro/(prejuízo líquido + patrimônio } \\
\text { líquido) }\end{array}$ & Alaoui et al. (2017) e Forte et al. (2013) \\
\hline Tamanho & $\begin{array}{l}\text { Logaritmo do número total de } \\
\text { ativos }\end{array}$ & $\begin{array}{l}\text { Alaoui et al. (2017), Bauer (2004), Céspedes } \\
\text { et al. (2010), Chen (2004), Choi e Richardson } \\
\text { (2016), Deesomsak et al. (2004), Eckbo e Norli } \\
\text { (2005), Forte et al. (2013), Gill et al. (2011), } \\
\text { Johnson (2003), Jong et al. (2008), Rajan e } \\
\text { Zingales (1995) e Titman e Wessels (1988). }\end{array}$ \\
\hline IPCA & $\begin{array}{l}\text { Índice de preços ao consumidor } \\
\text { amplo-Variação trimestral }\end{array}$ & $\begin{array}{l}\text { Deesomsak et al. (2004), Jong et al. (2008) } \\
\text { e Rajan e Zingales (1995) }\end{array}$ \\
\hline INAD & $\begin{array}{l}\text { Índice de inadimplência da carteira } \\
\text { de crédito- variação trimestral }\end{array}$ & $\begin{array}{l}\text { Deesomsak et al. (2004), Jong et al. (2008) } \\
\text { e Rajan e Zingales (1995) }\end{array}$ \\
\hline Ibovespa & Índice Bovespa-Média trimestral & $\begin{array}{l}\text { Deesomsak et al. (2004), Jong et al. } \\
\text { (2008) e Rajan e Zingales (1995) }\end{array}$ \\
\hline
\end{tabular}

Os índices apresentados na Tabela 1 possuem especificidades que demonstram a situação patrimonial da empresa. Para verificar o quanto uma empresa possui de ativos no curto e no longo prazo, utiliza-se a liquidez geral. Espera-se que um alto indicador de liquidez geral cause um efeito negativo na volatilidade da empresa (Deesomsak et al., 2004), pois a firma demonstra que pode saldar tanto as dívidas de curto prazo quanto as dívidas de longo prazo, uma vez que a diminuição do passivo da empresa eleva o indicador de liquidez geral, conforme se demonstra na primeira linha da Tabela 1.

A análise da maturidade das dívidas foi operada pela composição do endividamento, que indica o percentual da dívida, a qual tem a obrigação de ser quitada no curto prazo, conforme se apresenta na segunda linha da Tabela l. A composição do endividamento é uma proporção entre passivo circulante e passivo não circulante. De modo geral, espera-se que os índices que refletem o endividamento ou as dívidas de uma empresa possuam um efeito positivo na volatilidade; quanto maior for o nível de dívidas, maior será o risco de falência de uma firma. Isso está de acordo com os resultados encontrados por Alaoui et al. (2017), que foram efeitos prejudiciais da dívida sobre a volatilidade das empresas com alto endividamento e um efeito positivo na volatilidade das empresas com baixo nível de endividamento.

Adicionalmente, a participação de recursos de terceiros na estrutura de capital será explorada mediante o Grau de Alavancagem Financeira (GAF); este avalia como o capital de terceiros influencia a rentabilidade de seus proprietários, sendo a fórmula exposta na 
terceira linha da Tabela 1. Se o custo do endividamento for menor que o retorno produzido pela aplicação do capital, o grau de alavancagem financeira será maior que 1, indicando que é financeiramente benéfico se endividar. Choi e Richardson (2016) e Ericsson et al. (2016) encontraram efeitos significativos da alavancagem financeira com relação à volatilidade.

Completando os índices financeiros para a análise do patrimônio, tem-se a imobilização do patrimônio líquido dado pela razão entre o ativo permanente e o patrimônio líquido. Esse indicador possui como objetivo indicar a quantia do patrimônio líquido que está aplicada no ativo permanente, conforme se apresenta na quarta linha da Tabela 1. Logo, supõe-se que a imobilização apresenta um efeito negativo sobre o risco, já que em caso de falência o imobilizado poderá ser usado para saldar as dívidas (Rajan \& Zingales, 1995).

Visando analisar a lucratividade, tem-se o Return On Equity (ROE). Segundo Assaf (2015), o "ROE representa a taxa de crescimento da rentabilidade do capital próprio de uma empresa. Assim, quanto maior for o ROE, mais a empresa é atrativa para os acionistas" ( $p$. 238), o que pode ser visto como um risco para os novos investidores. O ROE é estipulado pela relação entre lucro/prejuízo líquido e patrimônio líquido.

Além disso, conforme Deesomsak et al. (2004), Jong et al. (2008) e Rajan e Zingales (1995), é necessário introduzir variáveis que captem as especificidades de cada país para a análise da estrutura de capital das empresas. Para se capturar a variação de preços na economia, optou-se pelo uso do Índice Nacional de Preços ao Consumidor Amplo (IPCA), fornecido pelo IBGE, que mede o custo de vida entre famílias que recebem de 1 a 40 salários mínimos. Complementarmente, usa-se o índice de inadimplência da carteira de crédito (INAD), disponível no site do Banco Central do Brasil, ou seja, conforme o quanto de crédito está disponível para ser emprestado para as empresas, a inadimplência pode influenciar o custo de capital e as formas de financiamento. Esse índice tem a finalidade de identificar problemas na carteira de crédito dos bancos.

Por fim, como proxy para verificar o desempenho das ações, usa-se a média trimestral do Índice Bovespa (Ibov), conforme aparece na última linha da Tabela l, o que permitirá observar a relação entre a volatilidade das empresas e o principal índice do mercado financeiro brasileiro. Todas as variáveis macroeconômicas escolhidas são essenciais para avaliar o desempenho da economia brasileira.

A base de dados foi construída a partir de informações divulgadas pela Brasil, Bolsa, Balcão desde 2010 até o primeiro trimestre de 2017. Essa base consiste em 126 empresas e 3.625 observações, ou seja, tem-se um painel não balanceado com apenas 29 observações faltantes. Com relação ao preço dos ativos, são informações divulgadas em relatórios de transações diários, enquanto os balanços são informações trimestrais.

Nesse conjunto de dados há ativos que eram considerados como não líquidos, o que poderia ocasionar problema de transação não sincronizada e enviesar a estimativa 
da volatilidade. Portanto, estipulou-se um volume mínimo de 15 transações mensais. Para transações diárias, o número de empresas era muito pequeno, o que impossibilitaria a realização deste estudo.

As séries macroeconômicas foram extraídas de fontes oficiais do governo. O IPCA foi coletado do Instituto Brasileiro de Geografia e Estatística e o Índice de Inadimplência do Sistema Gerador de Séries Temporais do Banco Central. Já o Índice Bovespa foi extraído da B3.

Desse modo, a Tabela 2 apresenta as estatísticas descritivas das variáveis que serão utilizadas nas estimativas. Pode-se notar que as volatilidades dos ativos da amostra têm média de aproximadamente 2.5, sendo superior aos valores encontrados por Johnson (2003).

Na média, a alavancagem financeira das empresas é de 1.2, entretanto, há uma grande variação entre as empresas da amostra, dado um alto desvio padrão de 30.03. $O$ valor mínimo para a liquidez geral é de 0.08, referente à Metalúrgica Gerdau S.A.

Tabela 2

Estatísticas descritivas

\begin{tabular}{lrrrrr}
\hline \multicolumn{1}{c}{ Variável } & \multicolumn{1}{c}{ Obs. } & Média & Desvio padrão & Mín. & Máx. \\
\hline Volatilidade & 3625 & 2.49 & 1.32 & 0.17 & 20.66 \\
\hline Liquidez geral & 3594 & 1.18 & 1.01 & 0.08 & 14.24 \\
\hline Composição do endividamento & 3594 & 0.47 & 0.22 & 0.01 & 1.00 \\
\hline Imobilização & 3538 & 1.09 & 12.61 & -170.00 & 694.55 \\
\hline ROE & 3538 & -0.10 & 7.05 & -416.70 & 20.31 \\
\hline Alavancagem & 3296 & 1.21 & 30.40 & -742.12 & 1044.33 \\
\hline Tamanho & 3538 & 22.39 & 1.76 & 14.99 & 27.96 \\
\hline IPCA & 3625 & 1.63 & 0.72 & 0.50 & 3.78 \\
\hline Ibovespa & 3625 & 10.94 & 0.12 & 10.70 & 11.15 \\
\hline Taxa de inadimplência & 3625 & 3.36 & 0.34 & 2.85 & 4.01 \\
\hline
\end{tabular}

Adicionalmente, a composição do endividamento possui média igual a 0,47 , o que significa que na média $47 \%$ do endividamento das empresas é de curto prazo e possui pouca variação entre as empresas. Por outro lado, tem-se que o endividamento das empresas no curto prazo é de $1 \%$ e o máximo é de $100 \%$.

Na média, as empresas da amostra possuem o imobilizado 1,09 vezes maior que o patrimônio líquido, com um desvio padrão de 12.61, o significa que os valores da amostra variam bastante. Com relação aos retornos sobre o patrimônio líquido ( $R O E)$, a média dos retornos é negativa, de $-10 \%$, e possui uma alta variação entre as empresas da amostra, dado o seu desvio padrão de 7.05. 


\section{MÉTODO}

Para se realizar a análise empírica são utilizados estimadores de dados em painel no software R. Dessa forma, pode-se analisar se há efeitos específicos em uma determinada firma. Segue-se Angrist e Pischke (2009) e testa-se a seguinte relação linear:

$$
y_{i t}=\alpha+\lambda_{t}+X_{i t} \beta+A_{i} \gamma+\varepsilon_{i t}
$$

Deve-se notar que tanto as variáveis explicativas tanto a explicada possuem variabilidade no tempo. No modelo de efeitos fixos, a heterogeneidade entre cada empresa é representada pela mudança paramétrica na Equação 1. É como se um novo intercepto $\alpha_{i}=\alpha+A_{i}^{\prime} \gamma$, que não varia com relação ao tempo, fosse incluso na estimativa de mínimos quadrados ordinários. De outro modo, fatores não observáveis que poderiam estar correlacionados com a variável dependente e com alguma variável explicativa são considerados constantes ao longo do tempo. Dessa forma, a Equação 2 toma a seguinte forma:

$$
y_{i t}=\alpha+\lambda_{t}+X_{i t} \beta+\varepsilon_{i t}
$$

Destaca-se que o termo representa $\lambda_{t}$, uma tendência temporal, ou seja, dummies referentes a cada ano. Por outro lado, no caso de efeitos aleatórios, o termo de heterogeneidade individual é considerado como parte do resíduo, $u_{i t}=A_{i}^{\prime} \gamma+\varepsilon_{i}$. Tendo por base essas especificações, realizou-se o teste de Hausman e constatou-se que deveria ser utilizado o painel com efeito fixo (FE). Com o objetivo de superar a heterocedasticidade indicada pelo teste de Breuch-Pagan e uma possível não normalidade dos resíduos da regressão, utilizaram-se erros padrões robustos em todas as estimações.

Os modelos de ARCH e GARCH são comumente utilizados para estimação de volatilidade em mercados acionários (Choi \& Richardson, 2016; Engle \& Ng, 1993; Nelson, 1991). Como não há observações suficientes para estimar a volatilidade em cada trimestre, utilizou-se o desvio padrão como medida de volatilidade. Pode-se destacar que o desvio padrão foi construído a partir do preço de fechamento diário. Separou-se os preços a cada mês e agrupamos no trimestre, assim, por exemplo, o trimestre 1 diz respeito aos preços dos meses de janeiro, fevereiro e março de 2010. Sendo a volatilidade a variável de interesse deste estudo, deseja-se então estimar a seguinte equação linear: 


$$
y_{i t}=\alpha_{i}+\beta_{0}+\beta_{1} G A F_{i t}+\sum_{i=2}^{n} \beta_{i} x_{i t}+\sum_{j=1}^{k} \gamma_{j} M_{j}+\sum_{b=2010}^{2017} \lambda_{b}+\varepsilon_{i t}
$$

Tem-se que GAF representa o grau de alavancagem da empresa i no período $t$, o vetor $x_{i t}$ refere-se às variáveis que estão relacionadas à estrutura patrimonial das firmas; o vetor $M_{j}$ representa um conjunto de variáveis macroeconômicas trimestrais, tendo início no primeiro trimestre de 2010 e fim no primeiro de 2017, contabilizando 29 trimestres, que permitem controlar efeitos de choques e das expectativas na economia; o termo é o efeito fix; e representa dummies de ano. $O$ grau de alavancagem financeira é padronizado em uma escala de 0 a 100 para possibilitar uma melhor interpretação dos coeficientes nas regressões.

\section{RESULTADOS}

Primeiramente se realizam as estimativas considerando apenas as variáveis referentes à estrutura de capital da empresa, para verificar seu efeito na variação da volatilidade dos ativos. Destaca-se que foram adicionadas dummies temporais em todas as regressões, tendo como referência o ano de 2010. A Tabela 3 apresenta as estimativas:

Tabela 3

Efeitos da estrutura de capital na volatilidade dos ativos

\begin{tabular}{lccccc}
\hline & $(1)$ & $(2)$ & $(3)$ & $(4)$ & $(5)$ \\
\hline Alavancagem & $0.0153^{* * *}$ & $0.0167^{* * *}$ & $0.0167^{* * *}$ & $0.0167^{* * *}$ & $0.0168^{* * *}$ \\
& $(0.0039)$ & $(0.0036)$ & $(0.0036)$ & $(0.0036)$ & $(0.0036)$ \\
\hline Liquidez geral & $-0.1782^{*}$ & $-0.2094^{*}$ & $-0.2100^{*}$ & $-0.2101^{*}$ & $-0.2423^{*}$ \\
& $(0.0968)$ & $(0.1171)$ & $(0.1174)$ & $(0.1175)$ & $(0.1279)$ \\
\hline Composição de endividamento & & 1.1507 & 1.1509 & 1.1506 & 1.0842 \\
& & $(0.7302)$ & $(0.7305)$ & $(0.7306)$ & $(0.7049)$ \\
\hline Imobilizacão & & & -0.0012 & -0.0012 & -0.0008 \\
& & & $(0.0010)$ & $(0.0010)$ & $(0.0010)$ \\
\hline ROE & & & -0.0006 & $0.0054^{*}$ \\
& & & & $(0.0004)$ & $(0.0028)$ \\
\hline Tamanho & & & & $-0.3518^{* *}$ \\
\hline Constante & & & & $(0.1697)$ \\
\hline
\end{tabular}




\begin{tabular}{lrrrrr}
\hline & \multicolumn{1}{c}{$(1)$} & \multicolumn{1}{c}{$(2)$} & \multicolumn{1}{c}{$(3)$} & $(4)$ & $(5)$ \\
\hline $\mathrm{N}$ & $(0.1962)$ & $(0.3988)$ & $(0.4002)$ & $(0.4002)$ & $(3.6125)$ \\
\hline adj. $R^{2}$ & 3274 & 3274 & 3274 & 3274 & 3274 \\
\hline Teste F & 0.145 & 0.156 & 0.156 & 0.156 & 0.163 \\
\hline
\end{tabular}

Nota. Erros padrões robustos entre parênteses: ${ }^{*}$ significativo a $10 \%,{ }^{* *}$ significativo a $5 \%$ e ${ }^{* * *}$ significativo a $1 \%$.

Foram incluídas dummies temporais em todas as estimativas.

Verificou-se que a alavancagem financeira se mostrou significativa em todos os modelos, de modo que um aumento do grau de alavancagem das empresas eleva o desvio padrão do retorno dos ativos.

O índice de liquidez geral apresentou efeitos significativos apenas ao nível de 10\%, mostrando que a capacidade da empresa em saldar as dívidas no longo prazo possui um efeito negativo sobre a volatilidade. Em média, o aumento de um ponto percentual na liquidez geral reduz em aproximadamente 0.2 o desvio padrão do retorno dos ativos.

O tamanho também apresenta efeito negativo sobre a volatilidade, conforme esperado. Em outras palavras, empresas maiores, ou seja, que possuem um maior número de ações no mercado apresentam em média uma menor volatilidade no preço dos seus ativos. Esse resultado está de acordo com o trabalho de Calvino, Criscuolo, Menon, e Secchi (2018), que demonstrou a existência de uma relação negativa robusta entre volatilidade e tamanho das empresas. Dada a significância do $R O E$, pode-se notar que o lucro possui mais impacto na volatilidade das empresas do que na oportunidade de crescimento, em que se privilegia os acionistas mais antigos do que os novos investidores.

A seguir realizam-se as estimativas utilizando-se os controles macroeconômicos. Tomase como base o modelo completo apresentado na Equação 3.

Tabela 4

Efeitos da estrutura de capital na volatilidade dos ativos com controles macroeconômicos

\begin{tabular}{lcrr}
\hline & $(1)$ & $(2)$ & $(3)$ \\
\hline Alavancagem & $0.0171^{\cdots * *}$ & $0.0152^{\cdots * *}$ & $0.0154^{\cdots *}$ \\
\hline Liquidez geral & $(0.0037)$ & $(0.0029)$ & $(0.0031)$ \\
\hline Composição de endividamento & $-0.2379^{*}$ & $-0.2218^{*}$ & $-0.2219^{*}$ \\
& $(0.1280)$ & $(0.1282)$ & $(0.1276)$ \\
\hline Imobilização & 1.0696 & 1.0739 & 1.0678 \\
& $(0.7037)$ & $(0.6975)$ & $(0.6987)$ \\
\hline ROE & -0.0007 & -0.0007 & -0.0007 \\
& $(0.0011)$ & $(0.0010)$ & $(0.0010)$ \\
\hline
\end{tabular}




\begin{tabular}{|c|c|c|c|}
\hline & & $(2)$ & (3) \\
\hline & $(0.0028)$ & (0.0028) & (0.0029) \\
\hline \multirow[t]{2}{*}{ Tamanho } & $-0.3488^{* *}$ & $-0.3713^{* *}$ & $-0.3650^{* *}$ \\
\hline & (0.1699) & $(0.1732)$ & $(0.1741)$ \\
\hline \multirow[t]{2}{*}{ IPCA } & $0.0766^{* * *}$ & 0.0102 & 0.0219 \\
\hline & $(0.0219)$ & (0.0197) & (0.0201) \\
\hline \multirow[t]{2}{*}{ Ibovespa } & & $-3.4073^{* *}$ & $-3.3998^{* * *}$ \\
\hline & & $(0.3081)$ & $(0.3093)$ \\
\hline \multirow[t]{2}{*}{ Taxa de inadimplência } & & & $0.1784^{*}$ \\
\hline & & & $(0.0954)$ \\
\hline \multirow[t]{2}{*}{ Constante } & $8.8149^{* *}$ & $47.3207^{* * *}$ & $46.4568^{* * *}$ \\
\hline & $(3.6156)$ & $(5.6719)$ & $(5.8870)$ \\
\hline $\mathrm{N}$ & 3274 & 3274 & 3274 \\
\hline $\operatorname{adj} \cdot R^{2}$ & 0.165 & 0.217 & 0.218 \\
\hline Teste F & $19.3707^{* * *}$ & $26.3865^{* *}$ & $26.4204^{* * *}$ \\
\hline
\end{tabular}

Quando se estimou o modelo adicionando as variáveis macroeconômicas, a alavancagem continua apresentando um efeito significativo e positivo. Pode-se notar também que as variáveis de liquidez geral, o tamanho e ROE mantiveram os mesmos sinais e praticamente a mesma magnitude das estimativas anteriores, de modo que os resultados se mostram robustos para especificações diferentes das variáveis de controle.

Ao adicionar o Índice Bovespa nos modelos 2 e 3 tem-se que um aumento de um ponto percentual faz com que a volatilidade caia em 3.4 desvios padrões. $O$ aumento de um ponto percentual é um acréscimo bastante relevante, considerando que esse indicador possui média 10.9 e desvio padrão 0.12. Logo, o aumento do índice diminui a volatilidade das firmas, o que já era um efeito esperado porque o índice é uma amostra do mercado financeiro brasileiro, logo um aumento no índice significa um aumento no valor das empresas, o que diminui o risco de falência. $O$ índice de inadimplência apresentou-se significativo, sendo que um aumento de 1 ponto percentual nesse indicador aumenta a volatilidade em 0.18 desvio padrão.

A próxima análise consiste na separação amostral das empresas que possuem um índice de endividamento maior que 1. Esse indicador é construído pela razão do passivo sobre o patrimônio líquido, sendo que na base de dados deste estudo $60 \%$ das firmas apresentam essa razão sendo maior que 1. Conforme indicam Alaoui et al. (2017), o grau de endividamento pode aumentar a volatilidade das empresas. 
Tabela 5

Efeitos da estrutura de capital na volatilidade dos ativos com controles macroeconômicos-Empresas com endividamento maior que 1

\begin{tabular}{|c|c|c|c|}
\hline & (1) & (2) & (3) \\
\hline \multirow[t]{2}{*}{ Alavancagem } & $0.0177^{* * *}$ & $0.0158^{* * *}$ & $0.0160^{* * *}$ \\
\hline & $(0.0041)$ & $(0.0032)$ & $(0.0034)$ \\
\hline \multirow[t]{2}{*}{ Liquidez geral } & $-0.8317^{* * *}$ & $-0.7651^{* * *}$ & $-0.7562^{* * *}$ \\
\hline & $(0.2401)$ & $(0.2346)$ & $(0.2360)$ \\
\hline \multirow[t]{2}{*}{ Composição de endividamento } & $1.1990 *$ & $1.1441^{*}$ & $1.1275^{*}$ \\
\hline & $(0.4766)$ & $(0.4472)$ & $(0.4491)$ \\
\hline \multirow[t]{2}{*}{ Imobilização } & 0.0012 & 0.0013 & 0.0013 \\
\hline & $(0.0014)$ & $(0.0013)$ & $(0.0013)$ \\
\hline \multirow[t]{2}{*}{ ROE } & $0.0064^{* * *}$ & $0.0069^{* * *}$ & $0.0066^{* * *}$ \\
\hline & $(0.0024)$ & $(0.0024)$ & $(0.0024)$ \\
\hline \multirow[t]{2}{*}{ Tamanho } & $-0.4249^{* * *}$ & $-0.4734^{* * *}$ & $-0.4645^{* *}$ \\
\hline & $(0.1459)$ & $(0.1481)$ & $(0.1481)$ \\
\hline \multirow[t]{2}{*}{ IPCA } & $0.0646^{* * *}$ & 0.0034 & 0.0152 \\
\hline & $(0.0222)$ & $(0.0204)$ & $(0.0223)$ \\
\hline \multirow[t]{2}{*}{ Ibovespa } & & $-3.1921^{* * *}$ & $-3.1845^{* * *}$ \\
\hline & & $(0.2799)$ & $(0.2794)$ \\
\hline \multirow[t]{2}{*}{ Taxa de inadimplência } & & & 0.1810 \\
\hline & & & $(0.1167)$ \\
\hline \multirow[t]{2}{*}{ Constante } & $10.9883^{* * *}$ & $47.6534^{* * *}$ & $46.7222^{* *}$ \\
\hline & $(3.3732)$ & $(5.0850)$ & $(5.0966)$ \\
\hline $\mathrm{N}$ & 2081 & 2081 & 2081 \\
\hline $\operatorname{adj.} R^{2}$ & 0.192 & 0.261 & 0.262 \\
\hline Teste F & $8.9253^{* * *}$ & $14.9761^{* * *}$ & $15.6825^{* * *}$ \\
\hline
\end{tabular}

Ao dividir a amostra, a magnitude dos efeitos sobre as variáveis que determinam a estrutura de capital e as condições macroeconômicas não se alteram. Pode-se notar que a liquidez geral apresenta um efeito negativo. Por exemplo, no modelo 3, um aumento de um ponto percentual nesse indicador reduz em 0.8 desvio a volatilidade. Esse efeito pode indicar que para as companhias com maior endividamento a capacidade de saldar as dívidas no longo prazo possui um efeito negativo sobre a volatilidade.

A composição do endividamento apresenta efeitos positivos na volatilidade, o que corrobora os resultados para a liquidez, já que a composição do endividamento se refere à 
porcentagem de dívidas que devem ser quitadas no curto prazo. No modelo 2 um aumento de um ponto percentual nesse indicador aumenta a volatilidade em 1.14 desvio padrão.

A seguir tem-se as estimativas para as companhias que apresentam o indicador de endividamento menor ou igual a 1 .

Tabela 6

Efeitos da estrutura de capital na volatilidade dos ativos com controles macroeconômicos-Empresas com endividamento menor ou igual a 1

\begin{tabular}{|c|c|c|c|}
\hline & 1) & (2) & (3) \\
\hline \multirow[t]{2}{*}{ Alavancagem } & -0.0241 & -0.0146 & -0.0121 \\
\hline & $(0.0504)$ & $(0.0506)$ & $(0.0517)$ \\
\hline \multirow[t]{2}{*}{ Liquidez geral } & -0.0981 & -0.0872 & -0.0880 \\
\hline & $(0.0935)$ & $(0.0961)$ & $(0.0957)$ \\
\hline \multirow[t]{2}{*}{ Composição do endividamento } & 0.7911 & 0.8509 & 0.8546 \\
\hline & $(1.2790)$ & $(1.2696)$ & $(1.2686)$ \\
\hline \multirow[t]{2}{*}{ Imobilização } & 0.0107 & 0.0112 & 0.0112 \\
\hline & (0.0109) & (0.0111) & $(0.0112)$ \\
\hline \multirow[t]{2}{*}{ ROE } & -0.0257 & -0.0151 & -0.0142 \\
\hline & $(0.0720)$ & $(0.0829)$ & $(0.0834)$ \\
\hline \multirow[t]{2}{*}{ Tamanho } & -0.1680 & -0.1847 & -0.1809 \\
\hline & $(0.3296)$ & $(0.3413)$ & $(0.3425)$ \\
\hline \multirow[t]{2}{*}{ IPCA } & $0.1153^{*}$ & 0.0335 & 0.0411 \\
\hline & $(0.0497)$ & $(0.0382)$ & $(0.0351)$ \\
\hline \multirow[t]{2}{*}{ Ibovespa } & & $-3.8781^{* * *}$ & -3.8746 \\
\hline & & $(0.7803)$ & $(0.7821)$ \\
\hline \multirow[t]{2}{*}{ Taxa de inadimplência } & & & 0.1186 \\
\hline & & & $(0.1831)$ \\
\hline \multirow[t]{2}{*}{ Constante } & 6.5800 & $49.6996^{* *}$ & 49.0512 \\
\hline & (7.5289) & (14.2044) & (14.5493) \\
\hline$N$ & 1193 & 1193 & 1193 \\
\hline $\operatorname{adj} . R^{2}$ & 0.075 & 0.130 & 0.130 \\
\hline Teste F & $5.80^{* * *}$ & $7.87^{* * *}$ & $7.36^{* *}$ \\
\hline
\end{tabular}

Nota. Erros padrões robustos entre parênteses: ${ }^{*}$ significativo a $10 \%,{ }^{* *}$ significativo a $5 \%$ e ${ }^{* * *}$ significativo a $1 \%$.

Foram incluídas dummies temporais em todas as regressões.

Com relação às estimativas anteriores, as variáveis que representam a estrutura patrimonial das empresas não apresentaram significância. Contudo, as variáveis macroeconômicas mantiveram o mesmo sinal. A magnitude do coeficiente do IPCA dobrou com relação ao modelo 1 da Tabela 5, isto é, um aumento de um ponto percentual nesse 
indicador aumenta em 0.12 desvio padrão a volatilidade. Os resultados para o Índice Bovespa são bastante próximos dos estimados anteriormente, porém, os coeficientes aumentam em aproximadamente 0.5 ponto percentual.

Adicionalmente, fez-se uma análise separando as empresas por setores. Para ter um número suficiente de dados setoriais, elencaram-se os ramos de atividade que possuíam pelo menos 200 observações. Desse modo, os setores selecionados foram os seguintes: construção civil, transportes, energia e de varejo. A seguir, apresentam-se as regressões para o setor de construção.

\section{Tabela 7}

Efeitos da estrutura de capital na volatilidade dos ativos com controles macroeconômicos-Setor de construção civil

\begin{tabular}{|c|c|c|c|}
\hline & & (2) & (3) \\
\hline \multirow[t]{2}{*}{ Alavancagem } & 0.0714 & 0.0903 & 0.0910 \\
\hline & $(0.0579)$ & $(0.0671)$ & $(0.0663)$ \\
\hline \multirow[t]{2}{*}{ Liquidez geral } & -0.6051 & -0.5905 & $-0.5982^{*}$ \\
\hline & $(0.3589)$ & $(0.3357)$ & $(0.3369)$ \\
\hline \multirow[t]{2}{*}{ Composição de endividamento } & 1.8415 & 1.5853 & 1.5968 \\
\hline & $(1.0536)$ & $(0.9689)$ & $(0.9860)$ \\
\hline \multirow[t]{2}{*}{ Imobilização } & $0.5087^{* * *}$ & $0.4945^{* * *}$ & $0.4906^{* * *}$ \\
\hline & $(0.0778)$ & $(0.0775)$ & $(0.0771)$ \\
\hline \multirow[t]{2}{*}{ ROE } & -1.6410 & -2.3000 & -2.2645 \\
\hline & $(1.5907)$ & $(1.7157)$ & $(1.7873)$ \\
\hline \multirow[t]{2}{*}{ Tamanho } & 0.2366 & 0.1179 & 0.1264 \\
\hline & $(0.5412)$ & $(0.5444)$ & $(0.5582)$ \\
\hline \multirow[t]{2}{*}{ IPCA } & 0.0231 & -0.0485 & -0.0427 \\
\hline & $(0.0487)$ & $(0.0334)$ & (0.0291) \\
\hline \multirow[t]{2}{*}{ Ibovespa } & & $-3.6200^{* * *}$ & $-3.6125^{* *}$ \\
\hline & & $(0.9596)$ & $(0.9727)$ \\
\hline \multirow[t]{2}{*}{ Taxa de inadimplência } & & & 0.0867 \\
\hline & & & $(0.2191)$ \\
\hline \multirow[t]{2}{*}{ Constante } & -6.1611 & $36.1111^{*}$ & $35.5145^{*}$ \\
\hline & $(12.6819)$ & (18.9227) & (19.9164) \\
\hline $\mathrm{N}$ & 370 & 370 & 370 \\
\hline $\operatorname{adj} . R^{2}$ & 0.249 & 0.342 & 0.340 \\
\hline Teste F & $1284^{* * *}$ & $67.16^{* *}$ & $82.35^{* * *}$ \\
\hline
\end{tabular}

Nota. Erros padrões robustos entre parênteses: ${ }^{*}$ significativo a $10 \%,{ }^{* *}$ significativo a $5 \%$ e ${ }^{* * *}$ significativo a $1 \%$.

Foram incluídas dummies temporais em todas as estimativas. 
Diferentemente das outras estimativas, para o setor de construção civil a imobilização das empresas, isto é, razão entre o ativo permanente e o patrimônio líquido apresentou uma relação positiva e significativa com a volatilidade. $O$ imobilizado se caracteriza por bens tangíveis que a firma não pretende se desfazer no curto prazo, por esse motivo, a sua liquidez é bastante baixa. Um aumento nesse indicador pode refletir a percepção dos agentes econômicos sobre decisões de investimento da companhia. Nesse caso, em média, o aumento de um ponto percentual nesse indicador acresce em 0.5 desvio padrão a volatilidade. A seguir tem-se as estimativas para o setor de varejo.

Tabela 8

Efeitos da estrutura de capital na volatilidade dos ativos com controles macroeconômicos-Setor de varejo

\begin{tabular}{|c|c|c|c|}
\hline & (1) & (2) & (3) \\
\hline \multirow{2}{*}{ Alavancagem } & $0.0086^{*}$ & 0.0073 & 0.0074 \\
\hline & $(0.0040)$ & $(0.0047)$ & $(0.0046)$ \\
\hline \multirow[t]{2}{*}{ Liquidez geral } & -0.0738 & 0.0059 & -0.0031 \\
\hline & $(0.4054)$ & $(0.4278)$ & $(0.4262)$ \\
\hline \multirow[t]{2}{*}{ Composição de endividamento } & $0.9558^{*}$ & $1.1788^{* *}$ & $1.1766^{\prime \prime}$ \\
\hline & $(0.5350)$ & $(0.5178)$ & $(0.5124)$ \\
\hline \multirow[t]{2}{*}{ Imobilização } & 0.0502 & 0.0444 & 0.0428 \\
\hline & $(0.1053)$ & $(0.1074)$ & $(0.1070)$ \\
\hline \multirow[t]{2}{*}{ ROE } & $-1.9691^{*}$ & $-2.0040^{*}$ & $-1.9993^{*}$ \\
\hline & $(0.9964)$ & $(1.0606)$ & $(1.0446)$ \\
\hline \multirow[t]{2}{*}{ Tamanho } & -0.5512 & -0.5467 & -0.5685 \\
\hline & $(0.6721)$ & $(0.6607)$ & $(0.6685)$ \\
\hline \multirow[t]{2}{*}{ IPCA } & -0.0241 & $-0.0779^{* *}$ & $-0.0840^{*}$ \\
\hline & $(0.0252)$ & $(0.0348)$ & $(0.0392)$ \\
\hline \multirow[t]{2}{*}{ Ibovespa } & & $-2.3460^{* * * *}$ & $-2.3463^{* * *}$ \\
\hline & & $(0.6653)$ & $(0.6676)$ \\
\hline \multirow[t]{2}{*}{ Taxa de inadimplência } & & & -0.0921 \\
\hline & & & $(0.2069)$ \\
\hline \multirow[t]{2}{*}{ Constante } & 12.9496 & $38.8973^{* * *}$ & $39.6894^{* * *}$ \\
\hline & (14.6095) & (10.8579) & (11.7616) \\
\hline $\mathrm{N}$ & 253 & 253 & 253 \\
\hline $\operatorname{adj} \cdot R^{2}$ & 0.108 & 0.170 & 0.167 \\
\hline Teste F & $604^{\cdots *}$ & $2128^{* *}$ & 2870 .". \\
\hline
\end{tabular}


Os resultados da Tabela 8 confirmam a hipótese que a alavancagem é uma variável explicativa relevante da volatilidade dos retornos para o setor de varejo. Este resultado pode ser reflexo pelo fato de esse setor ter níveis de endividamento mais elevados, corroborando as evidências encontradas na Tabela 5. Da mesma forma, o sinal positivo e significante da composição do endividamento indica que as empresas com maior endividamento de curto prazo tendem a ser mais afetadas em termos da volatilidade de seus ativos nesse setor. $\mathrm{Na}$ Tabela 9 estão os resultados para o setor de energia:

Tabela 9

Efeitos da estrutura de capital na volatilidade dos ativos com controles macroeconômicos-Setor de energia

\begin{tabular}{|c|c|c|c|}
\hline & (1) & $(2)$ & (3) \\
\hline \multirow[t]{2}{*}{ Alavancagem } & 0.0176 & 0.0152 & 0.0175 \\
\hline & $(0.0873)$ & $(0.1171)$ & $(0.1201)$ \\
\hline \multirow[t]{2}{*}{ Liquidez geral } & $-0.9258^{* * *}$ & $-0.9404^{* * *}$ & $-0.9243^{* * *}$ \\
\hline & $(0.1914)$ & (0.1909) & $(0.1735)$ \\
\hline \multirow[t]{2}{*}{ Composição de endividamento } & 0.9262 & 0.8866 & 0.9233 \\
\hline & $(0.7230)$ & $(0.8009)$ & $(0.7835)$ \\
\hline \multirow[t]{2}{*}{ Imobilização } & 0.2383 & 0.1866 & 0.1882 \\
\hline & $(0.3425)$ & $(0.3391)$ & $(0.3361)$ \\
\hline \multirow[t]{2}{*}{ ROE } & -0.1070 & 0.0416 & -0.0103 \\
\hline & $(0.2664)$ & $(0.2290)$ & $(0.1966)$ \\
\hline \multirow[t]{2}{*}{ Tamanho } & $-0.5685^{* * *}$ & $-0.5635^{* *}$ & $-0.5657^{* *}$ \\
\hline & $(0.1310)$ & $(0.1300)$ & $(0.1283)$ \\
\hline \multirow[t]{2}{*}{ IPCA } & $0.2533^{* * *}$ & $0.2192^{* * *}$ & $0.2368^{* * *}$ \\
\hline & $(0.0497)$ & $(0.0492)$ & $(0.0696)$ \\
\hline \multirow[t]{2}{*}{ Ibovespa } & & $-1.7221^{* * *}$ & $-1.7115^{* *}$ \\
\hline & & $(0.3719)$ & $(0.3774)$ \\
\hline \multirow[t]{2}{*}{ Taxa de inadimplência } & & & 0.2784 \\
\hline & & & $(0.4047)$ \\
\hline \multirow[t]{2}{*}{ Constante } & $14.1806^{* *}$ & $33.4353^{* * *}$ & $32.2552^{* * *}$ \\
\hline & $(5.8344)$ & $(4.9357)$ & $(4.2243)$ \\
\hline $\mathrm{N}$ & 229 & 229 & 229 \\
\hline $\operatorname{adj} . R^{2}$ & 0.343 & 0.373 & 0.374 \\
\hline Teste $\mathrm{F}$ & $501^{* *}$ & $765.38^{* * *}$ & $950 *$ \\
\hline
\end{tabular}

Nota. Erros padrões robustos entre parênteses: ${ }^{*}$ significativo a $10 \%,{ }^{* *}$ significativo a $5 \% e^{* * *}$ significativo a $1 \%$. Foram incluídas dummies temporais em todas as estimativas.

Para o setor de energia, a liquidez geral apresentou um coeficiente significativo em todos os modelos. Em média um aumento de um ponto percentual em um ponto percentual 
reduz a volatilidade em 0.9 desvio. Como esperado, o tamanho apresenta um efeito negativo e significativo em todos os modelos. Adicionalmente o IPCA e o Índice Bovespa se mostraram estatisticamente significativos em todos os modelos. Por fim, a Tabela 10 reporta os resultados para o setor de transportes.

Tabela 10

Efeitos da estrutura de capital na volatilidade dos ativos com controles macroeconômicos-Setor de transportes

\begin{tabular}{|c|c|c|c|}
\hline & (1) & (2) & (3) \\
\hline \multirow[t]{2}{*}{ Alavancagem } & $0.0095^{* * *}$ & $0.0126^{* *}$ & $0.0127^{*}$ \\
\hline & $(0.0027)$ & $(0.0040)$ & $(0.0039)$ \\
\hline \multirow[t]{2}{*}{ Liquidez geral } & $-1.7804^{* \cdots *}$ & $-1.6652^{* * *}$ & $-1.6783^{* * *}$ \\
\hline & $(0.4359)$ & $(0.4543)$ & $(0.4429)$ \\
\hline \multirow[t]{2}{*}{ Composição de endividamento } & 0.6718 & 0.3976 & 0.4075 \\
\hline & $(0.4178)$ & $(0.4374)$ & $(0.4393)$ \\
\hline \multirow[t]{2}{*}{ Imobilização } & $0.1774^{* * *}$ & $0.1700^{* * *}$ & $0.1702 \cdots$ \\
\hline & $(0.0319)$ & $(0.0398)$ & $(0.0405)$ \\
\hline \multirow[t]{2}{*}{ ROE } & -0.0564 & -0.0704 & -0.0699 \\
\hline & $(0.1477)$ & $(0.1591)$ & $(0.1603)$ \\
\hline \multirow[t]{2}{*}{ Tamanho } & $-0.7198^{* * * *}$ & $-0.7681^{* *}$ & $-0.7740 *$ \\
\hline & (0.1999) & $(0.2333)$ & $(0.2363)$ \\
\hline \multirow[t]{2}{*}{ IPCA } & 0.0743 & 0.0284 & 0.0225 \\
\hline & $(0.0810)$ & $(0.0810)$ & $(0.0898)$ \\
\hline \multirow[t]{2}{*}{ IBOVESPA } & & $-2.1919^{* * *}$ & $-2.1940 *$ \\
\hline & & $(0.5740)$ & $(0.5765)$ \\
\hline \multirow[t]{2}{*}{ Taxa de inadimplência } & & & -0.0792 \\
\hline & & & $(0.2269)$ \\
\hline \multirow[t]{2}{*}{ Constante } & $18.7618^{* \cdots}$ & $44.1113^{\cdots *}$ & $44.5507^{\cdots *}$ \\
\hline & $(4.5556)$ & (8.7208) & (8.9871) \\
\hline $\mathrm{N}$ & 225 & 225 & 225 \\
\hline Adj. $R^{2}$ & 0.486 & 0.517 & 0.515 \\
\hline Teste F & $18.82^{* * *}$ & $29.64^{* * *}$ & $31.1^{* \cdots}$ \\
\hline
\end{tabular}

Nota. Erros padrões robustos entre parênteses: ${ }^{*}$ significativo a $10 \%,{ }^{* *}$ significativo a $5 \%$ e ${ }^{* * *}$ significativo a $1 \%$. Foram incluídas dummies temporais em todas as estimativas.

Para o setor de empresas de transportes, a alavancagem se mostra estatisticamente significativa em todos os modelos. Pode-se notar que a liquidez geral também é estatisticamente significativa. A imobilização apresenta um efeito positivo e também significativo. $O$ indicador de tamanho e o índice também se apresentaram significativos em todos os modelos. 
Em linhas gerais, os resultados estão de acordo com os trabalhos de Alaoui et al. (2017), Bauer (2004), Céspedes et al. (2010), Choi e Richardson (2016), Eckbo e Norli (2005), Ericsson et al. (2016), Johnson (2003), Rajan e Zingales (1995) e Timan e Wessels (1988). Embora a análise seja distinta, há evidências de um efeito positivo da alavancagem financeira sobre a volatilidade dos ativos.

Além disso, a liquidez geral e o tamanho apresentaram sinais negativos. Isto é, a capacidade de saldar dívidas de curto, longo prazo e o número de ações da empresa afetam negativamente a volatilidade.

Já a imobilização e o ROE apresentaram sinais positivos. Empresas que apresentam um maior componente fixo (bens, edifícios, máquinas) sobre o seu patrimônio líquido têm volatilidade menor dos ativos, o que é especialmente evidenciado na análise setorial dos resultados. O retorno sobre o patrimônio líquido faz com que a volatilidade seja maior, ou seja, pode incentivar a compra de novas ações por parte dos investidores.

Entre as variáveis macroeconômicas, o Índice Bovespa apresenta um sinal negativo e estatisticamente significativo em grande parte das regressões. Um aumento nesse indicador reduz a volatilidade. Por fim, um aumento no índice de preços ao consumidor possui um efeito positivo na volatilidade, o que mostra que o ambiente econômico instável afeta a oscilação do preço das companhias de capital aberto.

\section{CONSIDERAÇÕES FINAIS}

O estudo dos determinantes da estrutura de capital de empresas que possuem ações em bolsa de valores é um dos principais temas discutidos em finanças corporativas. Desde o estudo clássico de Modigliani e Miller (1958) há diversos trabalhos que visam contribuir para esse tema, destacando-se os de Kraus e Litzenberger (1973), Myers e Majluf (1984) e Welch (2004).

Sob esse prisma, o objetivo deste artigo foi analisar o efeito da alavancagem financeira e a estrutura de capital na volatilidade das empresas listadas na B3. Para atingir tal meta se utilizou um modelo de dados em painel com efeito fixo, tendo como amostra 126 empresas de capital aberto no período de 2010 a 2017.

As evidências empíricas indicam que a alavancagem apresenta um efeito positivo e significativo sobre a volatilidade dos ativos. Esse resultado aparece principalmente para empresas com maior endividamento, bem como empresas do setor de transporte e varejo.

Ademais, as variáveis liquidez geral, Índice Bovespa e tamanho apresentam efeitos negativos sobre a volatilidade dos ativos. Uma empresa com maior liquidez possui uma maior capacidade de pagamento de suas dívidas tanto no curto quanto no longo prazo. 
O Índice Bovespa mede o desempenho médio das ações cotadas na bolsa de valores, um acréscimo nesse indicador dá subsídios para que em média o preço das ações oscile menos. A coeficiente negativo da variável tamanho indica que empresas maiores tendem a ter uma menor volatilidade no preço dos seus ativos. O IPCA e o ROE apresentaram sinais positivos.

O IPCA e o retorno sobre o patrimônio líquido apresentaram efeitos positivos. As flutuações na inflação podem indicar um ambiente econômico instável, o que afeta o valor de mercado das empresas negociadas em bolsa. Já um maior retorno sobre o patrimônio líquido pode incentivar com que novos investidores adquiram ações de determinada companhi, o que pode ser um incentivador para o acréscimo na volatilidade.

Em termos setoriais, viu-se que a imobilização é a razão do ativo permanente sobre - patrimônio líquido para as empresas dos setores de construção e de transportes. Por serem setores em que as companhias possuem máquinas e equipamentos caros para a execução da sua atividade fim, a decisão de imobilizar uma maior parte do seu patrimônio pode influenciar a percepção quanto ao preço dos agentes econômicos e assim aumentar a volatilidade do ativo.

Este artigo contribui com a literatura ao trazer evidências para o Brasil da relação entre a estrutura de capital das empresas de capital aberto e a volatilidade de seus ativos negociados em bolsa, observando os efeitos em diversos setores e empresas com características diferentes de endividamento.

Entre as limitações do artigo e possíveis temas para pesquisas futuras está a possibilidade de verificar como os resultados se comportam com medidas distintas de volatilidade das ações negociadas na B3. Adicionalmente, podem-se estudar os mecanismos por trás das decisões dos investidores e fundos de investimento que levam a uma maior volatilidade dos ativos de empresas que optam por aumentar seu financiamento por meio de capital de terceiros.

\section{REFERÊNCIAS}

Alaoui, A. O. el, Bacha, O. I., \& Masih, M. (2017). Leverage versus volatility: Evidence from the capital structure of European firms. Economic Modelling, 62, 145-160. Retrieved from https://www.sciencedirect.com/science/article/pii/S0264999316307702?via\%3Dihub https://doi.org/10.1016/j.econmod.2016.11.023

Angrist, J. D., \& Pischke, J. S. (2009). Mostly Harmless Econometrics: An Empiricist's Companion. Princeton: Princeton University Press.

Assaf, A. Neto. (2015). Estrutura e análise de balanços: Um enfoque econômico-financeiro. São Paulo: Atlas. 
Baker, S. H. (1973). Risk, leverage and profitability: An industry analysis. The Review of Economics and Statistics, 55(4), 503-507. Retrieved from https://www.jstor.org/stable/1925675

Bauer, P. (2004). Determinants of Capital Structure: Empirical evidence from the Czech Republic, Czech. Journal of Economics and Finance, 2-21.

Bouchaud, J. P., Matacz, A., \& Potters, M. (2001). The leverage effect in financial markets: Retarded volatility and market panic. Physical review letters, 22-26. Retrieved from https://journals.aps.org/prl/abstract/10.1103/PhysRevLett.87.228701

Bradley, M., Jarrel, G. A., \& Kim, E. H. (1984). On the existence of an optimal capital structure: theory and evidence. The Journal of Finance, 39, 857-878. doi:10.1111/j.1540-6261.1984. tb03680.x

Calvino, F., Criscuolo, C., Menon, C., \& Secchi, A. (2018). Growth volatility and size: A firm-level study. Journal of Economic Dynamics and Control, 90, 390-407.

Campbell, G., \& Rogers, M. (2018). Capital structure volatility in Europe. International Review of Financial Analysis, 55, 128-139.

Cardoso, G., Carr, D. D., \& Rogers, P. (2019). Does corporate governance matter for stock returns volatility in the Brazilian context? Corporate Governance: The International Journal of Business in Society.

Céspedes, J., González, M., \& Molina, C. A. (2010). Ownership and capital structure in Latin America. Journal of Business Research, 63(3), 248-254. Retrieved from https://www.sciencedirect.com/science/article/abs/pii/SO14829630900068X?via\%3Dihub

Chen, J. J. (2004). Determinants of capital structure of Chinese-listed companies. Journal of Business Research, 57(12), 1341-1351. Retrieved from https://www.sciencedirect.com/science/article/abs/pii/SO148296303000705?via\%3Dihub

Choi, J., \& Richardson, M. (2016). The Volatility of a firm's assets and the leverage effect. Journal of Financial Economics, 121(2), 254-277. Retrieved from https://www.sciencedirect. com/science/article/pii/S0304405X16301003?via\%3Dihub

Chon, B. U., \& Kim, H. (2019). Capital structure volatility, financial vulnerability, and stock returns: Evidence from Korean firms. Finance Research Letters, 30, 318-326.

DeAngelo, H., \& Roll, R. (2015). How stable are corporate capital structures? The Journal of Finance, 70(1), 373-418. 
Deesomsak, R., Paudyal, K., \& Pescetto, G. (2004). The determinants of capital structure: Evidence from the Asia Pacic region. Journal of Multinational Financial Management, 14(4-5), 387-405. Retrieved from https://www.sciencedirect.com/science/article/pii/ S1042444X04000039?via\%3Dihub

Eckbo, B. E., \& Norli, Ø. (2005). Liquidity risk, leverage and long-run IPO returns. Forthcoming Journal of Corporate Finance, 11(1-2), 1-35. Retrieved from https://www.sciencedirect.com/science/article/pii/SO929119904000276?via\%3Dihub

Engle, R. F., \& NG, V. K. (1993). Measuring and testing the impact of news on volatility. The Journal of Finance, 48(5), 1749-1778. Retrieved from https://onlinelibrary.wiley.com/doi/ full/10.1111/j.1540-6261.1993.tb05127.x

Ericsson, J., Huang, X., \& Mazzotta, S. (2016). Leverage and Asymmetric Volatility: The Firm-Level Evidence. Journal of Empirical Finance, 38(A), 1-21. Retrieved from https:// www.sciencedirect.com/science/article/abs/pii/S0927539816300226?via\%3Dihub

Forte, D., Barros, L. A., \& Nakamura, W. T. (2013). Determinants of the Capital Structure of Small and Medium Sized. Brazilian Administration Review, 10(3). Retrieved from http:// www.scielo.br/scielo.php?script=sci_arttext\&pid=S1807-76922013000300007\&lng=en\&t|$\mathrm{ng}=\mathrm{en}$

Gill, A., Biger, N., \& Mathur, N. (2011). The effects of capital structure on profitability: Evidence from United States. International Journal of Management, 28(4). Retrieved from https://www.researchgate.net/profile/Amarjit_Gill/publication/281004540_The_effects_ of_capital_structure_on_profitability_Evidence_from_United_States/links/578768ee08ae78057del8ede.pdf

Johnson, S. A. (2003). Debt maturity and the effects of growth opportunities and liquidity risk on leverage. The Review of Financial Studies, 16(1), 209-236. Retrieved from https:// academic.oup.com/rfs/article-abstract/16/1/209/1616950?redirectedFrom =fulltext

Jong, A., Kabir, R., \& Nguyen, T. T. (2008). Capital structure around the world: The roles of firm- and country-specific determinants. Journal of Banking \& Finance, 32(9), 1954-1969. Retrieved from https://www.sciencedirect.com/science/article/pii/ S0378426608000113?via\%3Dihub

Kraus, A., \& Litzenberger, R. H. (1973). A state preference model of optimal financial leverage. The journal of finance, 28(4), 911-922. Retrieved from https://onlinelibrary.wiley.com/ doi/abs/10.1111/j.1540-6261.1973.tb01415.x

Modigliani, F., \& Miller, M. H. (1958). The Cost of capital, corporation finance and the theory of investment. The American Economic Review, 48(3). Retrieved from https://www.jstor. $\mathrm{org} /$ stable/1809766?origin=JSTOR-pdf\&seq=1\#page_scan_tab_contents 
Myers, S. C., \& Majluf, N. (1984). Corporate financing and investment decisions when firms have information that investors do not have. Journal of Financial Economics, 13(2), 187-221. Retrieved from https://www.sciencedirect.com/science/article/pii/0304405X84900230?via\%3Dihub

Nelson, D. B. (1991). Conditional heteroskedasticity in asset returns: a new approach. Econometrica, 59(2), 347-370. Retrieved from https://www.jstor.org/stable/2938260

Oliveira, R. L., \& Kayo, E. K. (2019). The industry effect on firms' capital structure: Evidence from Brazil. Brazilian Review of Finance, 17(1), 1-18.

Rajan, R., \& Zingales, L. (1995). What do we know about capital structure? Some evidence from international data. Journal of Finance, 50(5), 1421-1460. Retrieved from https://onlinelibrary.wiley.com/doi/full/10.1111/j.1540-6261.1995.tb05184.x

Titman, S., \& Wessels, R. (1988). The Determinants of Capital Structure Choice. The Journal of Finance, 43(1), 1-19. Retrieved from https://onlinelibrary.wiley.com/doi/ full/10.1111/j.1540-6261.1988.tb02585.x

Welch, I. (2004). Capital Structure and Stock Returns. Journal of Political Economy, 112(1), 106-132. Retrieved from https://www.journals.uchicago.edu/doi/10.1086/379933

\section{Como citar este artigo:}

\section{ABNT}

OLIVEIRA, Fabio Michel; ELY, Regis Augusto; FERNANDEZ, Rodrigo Nobre. Alavancagem financeira, estrutura patrimonial e a volatilidade dos ativos negociados na B3. RACE, Revista de Administração, Contabilidade e Economia, Joaçaba: Editora Unoesc, v. 19, n. 3, p. 463-488, set./dez. 2020. Disponível em: http://editora.unoesc.edu.br/index.php/race. Acesso em: dia/mês/ano.

\section{APA}

Oliveira, F. M., Ely, R. A., \& Fernandez, R. N. (2020). Alavancagem financeira, estrutura patrimonial e a volatilidade dos ativos negociados na B3. RACE, Revista de Administração, Contabilidade e Economia, 19(3), 463-488. Recuperado de http://editora.unoesc.edu.br/ index.php/race 
